\title{
ANÁLISE ECONÔMICA DA CULTURA DO URUCUM (Bixa orellana) EM ADAMANTINA, SP
}

\author{
Eliana Cristina Generoso Konrad ${ }^{1}$, Maria Aparecida Anselmo Tarsitano²; Silvia Maria \\ Almeida Lima Costa ${ }^{2}$
}

\footnotetext{
${ }^{1}$ Engenheira Agrônoma, doutora em Agronomia - Sistema de Produção pela UNESP Campus de Ilha Solteira (SP). Email: eliana_generoso@bol.com.br.

${ }^{2}$ Docentes do Departamento de Fitotecnia, Tecnologia de Alimentos e Sócio Economia da UNESP - Campus de Ilha Solteira (SP). Email: maat@agr.feis.unesp.br; smalcost@agr.feis.unesp.br.
}

RESUMO: O Brasil é um dos maiores produtores de corantes naturais, com destaque para o urucum, um corantes mais utilizados pelas indústrias alimentícias. A Região da Nova Alta Paulista possui municípios que se destacam pela produção e produtos com altos teores de bixina. O presente trabalho discute um estudo de caso de uma exploração econômica de Urucum em propriedade de exploração familiar no município de Adamantina. Com o detalhamento do sistema de produção do urucuzeiro são levantadas inferências, para região de Adamantina, sobre a rentabilidade da cultura em condições de sequeiro. Houve aumento gradativo na produtividade, nos três anos consecutivos de cultivo. A evolução dos custos operacionais totais nas três primeiras colheitas para o módulo de quatro hectares da análise foram, respectivamente, $\mathrm{R} \$ 7.716,00, \mathrm{R} \$ 7.716,00$ e $\mathrm{R} \$ 7381,10$ e um lucro operacional para o mesmo período de $\mathrm{R} \$ 4.529,20, \mathrm{R} \$ 7.375,20$ e $\mathrm{R} \$ 12.726,90$, respectivamente. A capina, a poda e a colheita respondem pela maior parte do custo com mão-de-obra.

Palavras-chave: Bixa ollerana. Corante natural. Bixina. Custo de produção. Rentabilidade.

\section{ECONOMIC ANALYSIS OF ANNATTO (Bixa orellana) IN ADAMANTINA, SP}

\begin{abstract}
Brazil is one of the largest producers of natural dyes, especially the annatto widely used in food industries. The Region has Nova Alta Paulista municipalities that stand out for production and products with high levels of bixin. This paper conducted a study on a property of the municipality of Adamantina, SP., in order to identify the profitability of annatto under rainfed conditions. With details of the production system Urucuzeiro inferences to region. There was a gradual increase in productivity in the three consecutive years of cultivation. Total operating costs in four hectares of the crop planted in the first three harvests were respectively $\mathrm{R} \$ 7.716,00, \mathrm{R} \$ 7.716,00$ and $\mathrm{R} \$ 7381,10$ and an operating profit for the same period of $\mathrm{R} \$ 4.529,20, \mathrm{R} \$ 7.375,20$ and $\mathrm{R} \$ 12.726,90$, respectively. The weeding, pruning and harvest account for most of the cost of hand labor.
\end{abstract}

Key words: Bixa ollerana, Natural pigment, Production costs, Lucrativeness.

Cultura Agronômica, Ilha Solteira, v.24, n.1, p.93-102, 2015 


\section{INTRODUÇÃO}

Corantes alimentícios são utilizados para valorizar o aspecto visual do produto e a cor é um dos atributos mais importantes na comercialização de um alimento, favorecendo rejeição ou aceitação deste (TOCCHINI; MERCADANTE, 2001). O urucum (Bixa orellana) destaca-se entre os corantes naturais por ser atrativo, inócuo e por crescer espontaneamente na América do Sul (NAKANO, 1998).

Segundo Corlett et al. (2007), o urucuzeiro é uma planta originária da América do Sul, mais especificamente da região amazônica. Seu nome popular tem origem na palavra tupi "uru-ku", que significa vermelho, desta cultura, o produto de maior valor econômico advém da semente, que apresenta cobertura rica em bixina. A bixina é o pigmento (corante do grupo dos carotenóides), presente no pericarpo da semente e representa a matéria-prima relevante para a indústria de corantes, (FRANCO et al., 2008).

O urucum é utilizado como matéria-prima na fabricação de um dos corantes naturais mais difundidos na indústria de alimentos e responde por $70 \%$ na composição do conjunto de corantes naturais utilizados por esta indústria. $\mathrm{O}$ colorau ou colorífico, muito utilizado na culinária brasileira, a rigor não é considerado um corante, mas um condimento (GHIRALDI, 2011).

Dados do Levantamento Censitário das Unidades de Produção Agropecuária do Estado de São Paulo (LUPA), de 2007/2008 revelam existirem, à época, 426 Unidades de Produção Agropecuárias (UPAs/propriedades) em 2.370,5 hectares de área plantada com urucum. O EDR (Escritório de Desenvolvimento Rural) de Dracena foi responsável por 76,2 $\%$ deste total, neste território Monte Castelo destaca-se como principal município produtor. No município de Adamantina, o urucum representa uma cultura não tradicional, perfazendo apenas $0,17 \%$ da área agrícola cultivada (Levantamento Censitário das Unidades de Produção Agropecuária do Estado de São Paulo - LUPA, 2012).

O presente trabalho refere-se a um estudo de caso e teve por objetivo estimar, a partir de uma análise exploratória, o custo de produção do urucum, cultivar Piave, para o município de Adamantina, SP, Região da Nova Alta Paulista.

\section{MATERIAL E MÉTODOS}

\section{Caracterização da região de localização do município de Adamantina}

O município de Adamantina possui área territorial de 411,355 $\mathrm{km}^{2}$ e pertence ao EDR de Dracena, na região da Nova Alta Paulista, a oeste do estado de São Paulo. O EDR representa a unidade territorial de referência para planejamento da Coordenadoria de Assistência Técnica Integral (CATI) da Secretaria de Agricultura e Abastecimento do Estado de São Paulo. O EDR de Dracena engloba as Casas de Agricultura (CAs), dos seguintes municípios: Adamantina, Dracena, Flora Rica, Flórida Paulista, Irapuru, Junqueirópolis, Mariápolis, Monte Castelo, Nova Guataporanga, Ouro Verde, Pacaembu, Panorama, Paulicéia, Santa Mercedes, São João do Pau d'alho e Tupi Paulista. Estes 16 
municípios compreendem uma área agrícola de 444.647,2 ha (LUPA, 2012).

A Tabela 1 relaciona, por município, o número de unidades produtivas e as respectivas áreas cultivadas com a produção de urucum no EDR de Dracena.

Tabela 1. Caracterização dos municípios do EDR de Dracena, quanto à produção de urucum em 2008.

\begin{tabular}{lcc}
\hline MUNICÍPIO & NÚMERO DE UPAs* & ÁREA CULTIVADA (ha) \\
\hline Adamantina & 4 & 28,8 \\
Dracena & 3 & 6,6 \\
Flora Rica & - & - \\
Flórida Paulista & 1 & 14,0 \\
Irapuru & 7 & 52,2 \\
Junquierópolis & 34 & 149,3 \\
Mariápolis & 1 & 5,9 \\
Monte Castelo & 99 & 786,3 \\
Nova Guataporanga & 11 & 49,2 \\
Ouro Verde & 5 & 61,2 \\
Pacaembú & 1 & 0,7 \\
Panorama & 1 & 0,7 \\
Paulicéia & 16 & 32,1 \\
Santa Mercedes & 1 & 5,0 \\
São João do Pau D'alho & 64 & 384,3 \\
Tupi Paulista & 43 & 230,1 \\
\hline
\end{tabular}

*Unidades de Produção Agropecuária. Fonte: LUPA, 2012.

\section{Caracterização da propriedade}

A propriedade familiar tomada como referência para o estudo possui área de 24 ha no município de Adamantina. O proprietário é natural de Adamantina e possui como principal ocupação a agricultura. Das culturas agrícolas exploradas, o maracujá constitui a principal cultura (em área explorada e geração de renda) seguida por abacaxi. Além da mão-de-obra do núcleo familiar residente na propriedade, o produtor conta com a colaboração de outros membros da família (seu pai) para gerir a rotina das atividades. No período de colheita do urucum também se faz necessária contratação de mão-de-obra complementar (mais quatro pessoas) que recebem por horas trabalhadas.

Os dados sobre o cultivo do urucum foram levantados em entrevistas com o produtor em estudo de caso, nos meses de agosto e setembro de 2011, o qual autorizou a publicação das estimativas decorrentes da pesquisa. Neste caso, a descrição das despesas com mão de obra na produção do urucum, a unidade de trabalho é apontada em diárias, considerando-se o valor de $\mathrm{R} \$ 40,00$ (em valores do ano 2011).

\section{Caracterização do Sistema de Produção}

Para a implantação da cultura do urucum realiza-se preparo convencional do solo, adubação e aplicação de corretivo. As mudas foram adquiridas no viveiro municipal de Adamantina por $\mathrm{R} \$ 0,20$ a unidade. O manejo fitossanitário foi realizado para formigas e

Cultura Agronômica, Ilha Solteira, v.24, n.1, p.93-102, 2015 
plantas daninhas. O sistema de produção adotado pelo produtor em referência segue a tradição adotada no estado de São Paulo, como pode ser observado em Franco et al. (2008).

A cultura foi implantada em quatro hectares com espaçamento de $6 \times 4 \mathrm{~m}$, da cultivar Piave, no ano de 2007, em condição de sequeiro. A primeira, segunda e terceira colheita ocorreram nos anos de 2009, 2010 e 2011, respectivamente, e subsidiaram as informações para as estimativas de custos e lucratividade, identificadas neste trabalho.

Para proceder a colheita realizou-se podas de alguns galhos visando facilitar o acesso às panículas. Estes galhos foram deixados sob a copa das plantas, na entrelinha e posteriormente roçados, prática indicada para reduzir o volume da massa vegetal e acelerar a decomposição, operação incluída no orçamento de operações mecanizadas. A colheita foi realizada manualmente, com as panículas depositadas nas entrelinhas e enleiradas, para secar durante 20 dias. Após este período foram recolhidas em balaios, depositadas na carreta de trator e levadas para secar em pátio exposto ao sol. A colheita ocorre pelo período de 40 dias iniciando-se no mês de julho.

O beneficiamento considera o descachopamento (a retirada das sementes das cachopas) e a ventilação para eliminar particulados leves. O descachopamento é realizado por uma colhedeira de feijão adaptada e a ventilação é realizada pelo motor do trator.

Toda a produção é destinada à fabricação de corante alimentícios por aquisição da empresa Urucum do Brasil@, em Monte Castelo. Esta empresa representa um braço comercial de uma outra empresa, a Corantes Chr. Hansen Indústria e Comércio Ltda (Christian Hansen), que atua na produção de corantes naturais (a base de carmim, urucum e beterraba) utilizados como insumo para induústria alimentícia, em especial no processamento agroindustrial de produtos cárneos (CHR HANSEN, 2011).

Os grãos são comercializados em sacos de $50 \mathrm{~kg}$, fornecidos pela Urucum do Brasil®. Existem diferentes critérios para classificação das sementes (Tabela 2) quanto aos atributos de qualidade, no caso da região e sistema em análise, o critério mais utilizado é o de pagamento da produção, baseado em classificação segundo o teor de bixina e também na produtividade. As despesas para o transporte ocorreram por conta da empresa

Tabela 2. Classificação das sementes de urucum segundo o teor de bixina.

\begin{tabular}{lccc}
\hline \multirow{2}{*}{ ESPECIFICAÇÃO } & \multicolumn{3}{c}{ CLASSE } \\
\cline { 2 - 4 } & TIPO 1 & TIPO 2 & TIPO 3 \\
\hline Umidade & $\leq 10 \%$ & $>10$ a $14 \%$ & $>14 \%$ \\
Bixina & $>2,5 \%$ & 2,0 a $2,5 \%$ & $<1,8 \%$ \\
Impurezas & $<5 \%$ & $<5 \%$ & $>5 \%$ \\
Material estranho & Ausente & Ausente & Presente \\
\hline
\end{tabular}

Fonte: FRANCO et al., 2002.

\section{Análise Econômica}

O cálculo do custo de produção e os indicadores de lucratividade tomaram por base a metodologia detalhada em Martin et al. (1998). Os coeficientes técnicos para instalação e manutenção do urucum foram identificados junto ao produtor e adaptado segundo Franco et 
al. (2008). Estimou-se o custo operacional efetivo (COE) como as despesas com as operações mecanizadas e manuais e os insumos utilizados no sistema produtivo. Acrescentou-se ao COE outras despesas, que foram estimada como uma taxa de $5 \%$ sobre o COE obtendo-se o custo operacional total (COT).

Os indicadores de lucratividade estimados foram também segundo Martin et al. (1998), quais sejam:

- Receita Bruta (RB): receita esperada para determinada produção por hectare, para um preço de venda pré-definido ou efetivamente recebido: $\mathrm{RB}=\operatorname{Pr}$ x $\mathrm{Pu}$, onde $\operatorname{Pr}$ é a produção em $\mathrm{kg}$ por unidade de área e $\mathrm{Pu}$ o preço médio do $\mathrm{kg}$ recebido pelo produtor.

- Lucro Operacional (LO): constitui a diferença entre a receita bruta e o custo operacional total por hectare: $\mathrm{LO}=\mathrm{RB}-\mathrm{COT}$, onde COT é o custo operacional total de produção;

- Margem Bruta (MB): é a margem em relação ao custo operacional, isto é, o resultado obtido após o produtor arcar com o custo operacional, considerando determinado preço unitário de venda e a produtividade do sistema de produção para a atividade. Assim, esta margem indica qual a disponibilidade presente para cobrir o risco e a capacidade empresarial do proprietário. $\mathrm{MB}=(\mathrm{RB}-\mathrm{COT}) / \mathrm{COT} \times 100$;

- Índice de Lucratividade (IL): este indicador mostra a relação entre o lucro operacional e a receita bruta, em porcentagem. $\mathrm{IL}=(\mathrm{LO} / \mathrm{RB}) \times 100$;

- Ponto de nivelamento (PN): indicador de custo em relação à unidade do produto. $\mathrm{PN}=$ $\mathrm{COT} / \mathrm{Pu}$.

Ao final do levantamento dos dados estes foram tabulados, analisados e estruturados em planilhas no Excel®, visando identificar a viabilidade do urucum nas condições levantadas.

\section{RESULTADOS E DISCUSSÃO}

As relações comerciais de fornecimento para a empresa Urucum do Brasil, para a qual o produtor entrega toda a sua produção, não são intermediadas por contrato formal de fornecimento, outorgando ao produtor a possiblidade de arbitrar melhores condições de pagamento por outros compradores que efetuam aquisições na região com frequência menor do que faz aquela empresa.

No caso da propriedade em análise a primeira colheita se deu dois anos após a implantação da cultura.Tanto os custos de implantação como os custos de manutenção são considerados baixos na cultura do urucum, o que torna atraente a exploração desta cultura como interessante oportunidade de aproveitamento complementar dos recursos da propriedade, no caso em análise, o cultivo acontece na entressafra da principal exploração, a cultura do maracujá, viabilizando ao produtor atender a demanda de trabalho com o manejo da cultura do urucum, especialmente no período de colheita desta. 
O custo operacional total de implantação foi de $\mathrm{R} \$ 6.468,00 /$ ha. Deste total os insumos tiveram maior participação, quase $42 \%$ seguido pelas despesas com operações manuais (cerca de 32\%), as operações mecanizadas (com 21\%) e outras despesas (quase 0,5\%.). Do conjunto das despesas com insumos destaca-se o valor com aquisição de esterco de curral $\mathrm{R} \$ 1.680,00$ o que corresponde a quase dois terços do total com insumos. Em relação às operações manuais a despesa com operações de coveamento representou $61,5 \%$ do total gasto com mão-de-obra (Tabela 3).

Os custos operacionais totais foram iguais nos primeiros anos de produção (Ano 2 e Ano 3), as operações manuais representam $62 \%$ do COT, seguida pelas despesas com insumos com $26 \%$ e operações mecanizadas com quase $13 \%$.

Tabela 3. Estimativas de custos de implantação e manutenção do urucum, em 4 hectares, variedade Piave, em Adamantina, SP, 2011.

\begin{tabular}{|c|c|c|c|c|c|c|c|c|c|c|}
\hline \multirow[t]{3}{*}{ DESCRIÇÃO } & \multirow[t]{3}{*}{ Esp. } & \multirow{3}{*}{$\begin{array}{l}\text { V. } \\
\text { unit. }\end{array}$} & \multirow{2}{*}{\multicolumn{2}{|c|}{\begin{tabular}{|c|} 
Implantação \\
Ano 1
\end{tabular}}} & \multirow{2}{*}{\multicolumn{2}{|c|}{$\begin{array}{c}\text { Produção } \\
\text { Ano } 2\end{array}$}} & \multirow{2}{*}{\multicolumn{2}{|c|}{$\begin{array}{c}\text { Produção } \\
\text { Ano 3 }\end{array}$}} & \multirow{2}{*}{\multicolumn{2}{|c|}{$\begin{array}{c}\text { Produção } \\
\text { Ano } 4\end{array}$}} \\
\hline & & & & & & & & & & \\
\hline & & & Qtd. & Total & Qtd. & Total & Qtd. & Total & Qtd. & Total \\
\hline \multicolumn{11}{|c|}{ A. Operações Mecanizadas } \\
\hline Aração & HM & 30,00 & 12 & 360,00 & & & & & & \\
\hline Gradeação & HM & 30,00 & 10 & 300,00 & & & & & & \\
\hline Calagem & HM & 30,00 & 8 & 240,00 & & & & & & \\
\hline Roçagem & HM & 30,00 & 16 & 480,00 & & & & & & \\
\hline Transp. interno & HM & 30,00 & & & 5,5 & 165,00 & \begin{tabular}{|r|}
5,5 \\
\end{tabular} & 165,00 & 5,5 & 165,00 \\
\hline Roçar galhos & HM & 30,00 & & & 15,2 & 456,00 & 15,2 & 456,00 & 15,2 & 456,00 \\
\hline $\begin{array}{l}\text { Recolher e beneficiar } \\
\text { sementes }\end{array}$ & $\mathrm{HM}$ & 30,00 & & & 8,0 & 240,00 & 8,0 & 240,00 & 12,0 & 360,00 \\
\hline \multicolumn{3}{|l|}{ Subtotal A } & \multicolumn{2}{|r|}{$1.380,00$} & \multicolumn{2}{|r|}{861,00} & \multicolumn{2}{|r|}{861,00} & \multicolumn{2}{|r|}{981,00} \\
\hline \multicolumn{11}{|l|}{ B. Operações Manuais } \\
\hline Coveamento & $\mathrm{H} / \mathrm{d}$ & 40,00 & 32 & $1.280,00$ & & & & & & \\
\hline Coroamento & $\mathrm{H} / \mathrm{d}$ & 40,00 & 4 & 160,00 & & & & & & \\
\hline Adubação de plantio & $\mathrm{H} / \mathrm{d}$ & 40,00 & 8 & 320,00 & & & & & & \\
\hline Plantio de mudas & $\mathrm{H} / \mathrm{d}$ & 40,00 & 8 & 320,00 & & & & & & \\
\hline Controle de formiga & $\mathrm{H} / \mathrm{d}$ & 40,00 & & & 8 & 320,00 & 8 & 320,00 & 8 & 320,00 \\
\hline Capina & $\mathrm{H} / \mathrm{d}$ & 40,00 & & & 32 & $1.280,00$ & 32 & $1.280,00$ & 32 & 1280,00 \\
\hline Limpar as entrelinhas & $\mathrm{H} / \mathrm{d}$ & 40,00 & & & 8 & 320,00 & 8 & \begin{tabular}{|r|}
320,00 \\
\end{tabular} & 8 & 320,00 \\
\hline Pulverização & $\mathrm{H} / \mathrm{d}$ & 40,00 & & & 12 & 480,00 & 12 & 480,00 & 12 & 480,00 \\
\hline Adubação de cobertura & $\mathrm{H} / \mathrm{d}$ & 40,00 & & & 8 & 320,00 & 8 & 320,00 & 12 & 480,00 \\
\hline Poda & $\mathrm{H} / \mathrm{d}$ & 40,00 & & & 32 & $1.280,00$ & 32 & $1.280,00$ & 32 & $1.280,00$ \\
\hline Colheita & $\mathrm{H} / \mathrm{d}$ & 40,00 & & & 20 & 800,00 & 20 & \begin{tabular}{|r|}
800,00 \\
\end{tabular} & 40 & $1.600,00$ \\
\hline \multicolumn{3}{|l|}{ Subtotal B } & \multicolumn{2}{|r|}{$2.080,00$} & \multicolumn{2}{|r|}{$4.800,00$} & \multicolumn{2}{|r|}{$4.800,00$} & \multicolumn{2}{|c|}{$5.760,00$} \\
\hline \multicolumn{11}{|l|}{$\begin{array}{l}\text { C. INSUMOS } \\
\end{array}$} \\
\hline Esterco de curral & $\mathrm{t}$ & 70,00 & 24 & $1.680,00$ & & & & & & \\
\hline Superfosfato simples & sc $50 \mathrm{~kg}$ & 30,00 & \begin{tabular}{|l|}
12 \\
\end{tabular} & 360,00 & & & & & & \\
\hline Mudas & un. & 0,2 & 1700 & 340,00 & & & & & & \\
\hline Calcário & $\mathrm{t}$ & 160,00 & \begin{tabular}{|l|}
2 \\
\end{tabular} & 320,00 & & & & & 2 & 320,00 \\
\hline Fórmula 20-00-20 & sc $50 \mathrm{~kg}$ & 50,00 & & & 16 & 800,00 & 16 & 800,00 & 14 & 675,00 \\
\hline Inseticida & $\mathrm{g}$ & 1,00 & & & 534 & 534,00 & 534 & 534,00 & 534 & 534,00 \\
\hline Herbicida & $\mathrm{L}$ & 8,00 & & & 50,5 & 404,00 & 50,5 & 404,00 & \begin{tabular}{|l|}
34 \\
\end{tabular} & 272,00 \\
\hline \multicolumn{3}{|l|}{ Subtotal C } & \multicolumn{2}{|r|}{$2.700,00$} & \multicolumn{2}{|c|}{$1.738,00$} & \multicolumn{2}{|c|}{$1.738,00$} & \multicolumn{2}{|c|}{$1.801,00$} \\
\hline
\end{tabular}

Cultura Agronômica, Ilha Solteira, v.24, n.1, p.93-102, 2015 


\begin{tabular}{l|l|r|r|r|r|r|r}
\hline \hline Custo Oper. Efetivo & & & $\mathbf{6 . 1 6 0 , 0 0}$ & $\mathbf{7 . 3 9 9 , 0 0}$ & $\mathbf{7 . 3 9 9 , 0 0}$ & $\mathbf{6 . 9 2 2 , 0 0}$ \\
\hline Outras despesas & & & $\mathbf{3 0 8 , 0 0}$ & $\mathbf{3 1 7 , 9 5}$ & $\mathbf{3 1 7 , 9 5}$ & $\mathbf{4 5 9 , 1 0}$ \\
\hline Custo Oper. Total & & & $\mathbf{6 . 4 6 8 , 0 0}$ & $\mathbf{7 . 7 1 6 , 0 0}$ & $\mathbf{7 . 7 1 6 , 0 0}$ & $\mathbf{7 . 3 8 1 , 1 0}$ \\
\hline
\end{tabular}

Apesar do aumento nos custos com mão-de-obra no terceiro ano de produção houve redução no custo total de $\mathrm{R} \$ 7.381,10$ em relação os dois primeiros anos de produção. $\mathrm{O}$ aumento nos custos com operações manuais pode ser atribuído ao aumento da produtividade e como conseqüência a necessidade de contratar mais funcionários para operação de colheita, que, para este ano, sobrepôs às operações de poda em demanda por trabalho humano e valor na composição dos custos (Tabela 3 ).

A composição dos preços está vincula ao teor de bixina (corante) e à produtividade. Considerando-se o teor de bixina Tipo 1, identificado pelo comprador, nas três colheitas, o valor pago pelo quilo do produto $(\mathrm{R} \$ 0,80)$ e a produção nos respectivos anos $(2009,2010 \mathrm{e}$ 2011), tem-se a formação dos preços expressa abaixo:

- Teor de Bixina da Produção em $2009=6,05 \%$

- Produção em $2009=2.530 \mathrm{~kg}$

- Preço pago por $\mathrm{Kg}=\mathrm{R} \$ 0,80$

- Elaboração do preço final = 6,05 x R $\$ 0,80=\mathrm{R} \$ 4,84 / \mathrm{kg}$

- Valor recebido pela produção $=\mathrm{R} \$ 4,84$ x $2.530 \mathrm{~kg}=\mathrm{R} \$ 1.2245,20$

- Teor de Bixina da Produção em $2010=4,8 \%$

- Produção em $2010=3.930 \mathrm{~kg}$

- Preço pago por $\mathrm{Kg}=\mathrm{R} \$ 0,80$

- Elaboração do preço final = 4,8 x R $\$ 0,80=\mathrm{R} \$ 3,84 / \mathrm{kg}$

- Valor recebido pela produção $=\mathrm{R} \$ 3,84$ x $3.930 \mathrm{~kg}=\mathrm{R} \$ 15.091,20$

- Teor de Bixina da Produção em $2011=5,5 \%$

- Produção em $2011=4.570 \mathrm{~kg}$

- Preço pago por $\mathrm{Kg}=\mathrm{R} \$ 0,80$

- Elaboração do preço final $=5,5$ x R $\$ 0,80=\mathrm{R} \$ 4,40 / \mathrm{kg}$

- Valor recebido pela produção $=\mathrm{R} \$ 5,5 \times 4.570 \mathrm{~kg}=\mathrm{R} \$ 20.108,00$

$\mathrm{Na}$ Tabela 4 os valores recebidos por quilo de produto são pautados nos respectivos teores de bixina e produção, o aumento gradativo da produção guarda relação com o crescimento das plantas até o quinto ano (FRANCO et al. (2008), a partir deste ano, a produção do urucum estabiliza-se.

Tabela 4. Indicadores de lucratividade para a cultura do urucum, considerando-se quatro hectares, cultivar Piave, Adamantina, SP, 2011.

\begin{tabular}{l|c|c|c}
\hline Descrição & Ano 2 & Ano 3 & Ano 4 \\
\hline Valor por kg (R\$) & 4,84 & 3,84 & 4,40 \\
Produção (kg) & 2.530 & 3.930 & 4.570 \\
Margem Bruta (\%) & 58,7 & 95,6 & 172,43 \\
Receita bruta (R\$) & $12.245,20$ & $15.091,20$ & $20.108,00$ \\
Custo Operacional Total (R\$) & $7.716,00$ & $7.716,00$ & $7.381,10$ \\
Lucro Operacional (R\$) & $4.529,20$ & $7.375,20$ & $12.726,90$ \\
\hline
\end{tabular}

Cultura Agronômica, Ilha Solteira, v.24, n.1, p.93-102, 2015 
Índice de Lucratividade ( \%)

Produção de Nivelamento $(\mathrm{kg} /$ ciclo)

36,99

$1.594,20$

48,87

$2.009,37$

63,30

$1.677,53$

As produtividades auferidas para três anos do sistema de produção do urucum em análise, ou seja, de 632,5 kg/ha (2009), 982,5 kg/ha (2010) e 1.142,5 (2011) revelaram comportamento superior à média estadual para as duas primeiras colheitas, de acordo com o proposto por Franco et al. (2008), segundo o qual nos três primeiros anos de colheita do urucum no Estado de são Paulo a produtividade média foi de $500 \mathrm{~kg} / \mathrm{ha}, 800 \mathrm{~kg} / \mathrm{ha}$ e $1500 \mathrm{~kg} / \mathrm{ha}$. Esta mesma característica de desempenho foi apontada por Maia et al. (2010) em propriedades do assentamento rural da Microrregião de Dracena (SP), com indicativas de $500 \mathrm{~kg} / \mathrm{ha}$ (primeira colheita), $1.000 \mathrm{~kg} / \mathrm{ha}$ (segunda colheita) e $2.000 \mathrm{~kg} / \mathrm{ha}$ (terceira colheita), neste caso as duas maiores produtividades foram conseguidas na segunda e terceira colheita.

O maior índice de lucratividade, que pode ser considerado muito bom, foi obtido na terceira colheita, com $63,3 \%$. Segundo o produtor, maiores valores de produção poderiam ter sido praticados no terceiro ano de produção (Ano 4) caso a geada não tivesse afetado algumas plantas.

Assim que colhidas e embaladas as sementes foram enviadas para Monte Castelo, providência que demanda agilidade pelo fato de que, na propriedade, não serem efetuados as funções de acondicionamento refrigerado ou com controle de temperatura. Segundo Franco et al. (2008) a pós-colheita é uma prática de expressiva importância no processo agroindustrial do urucum, por interferir diretamente na qualidade do produto final. A póscolheita tem início no momento seguinte à colheita e compreende nas seguintes etapas: recolhimento dos frutos, descachopamento, peneiramento, secagem das sementes, ensacamento, armazenamento, classificação, beneficiamento e comercialização. O período de conservação de sementes de urucum pode exceder a 60 dias desde que a umidade das sementes e a temperatura de armazenamento (refrigeração a $10^{\circ} \mathrm{C}$ ) sejam adequadamente controladas (SANTANA et al., 2008).

Sementes de urucum com teores menores que 2,5 gramas de carotenóides totais expressos como bixina por $100 \mathrm{~g}$ de sementes (base úmida), ou seja, sementes identificadas por valores de bixina inferiores a 2,5\% encontram dificuldades de comercialização, por diminuírem muito o rendimento industrial e a qualidade do produto final, no caso, o corante (CARVALHO et al., 2010).

As estimativas de custos de produção podem apresentar grande variabilidade, dependendo da região, uma vez que decorrem de variações nos custos com insumos e com mão de obra. Segundo Franco (2011) a partir do $5^{\circ}$ ano, a receita líquida pode ser de US\$ 935,20/ha/ano, considerando-se uma produtividade estabilizada de $1.500 \mathrm{~kg} / \mathrm{ha} /$ ano ao preço de US\$1,00/kg de grãos.

\section{CONCLUSÕES}

De acordo com os resultados obtidos neste trabalho pode-se constatar que o urucum é

Cultura Agronômica, Ilha Solteira, v.24, n.1, p.93-102, 2015 
uma atividade rentável, característica que se associa a baixa exigência em tratos culturais. A maior demanda por mão-de-obra em relação a outras despesas ocorre na entressafra da cultura do maracujá, o que revela uma associação de explorações adequada para sistemas de produção de caráter familiar. A mão-de-obra utilizada na colheita é um dos itens que mais onera o custo de produção do urucum, pois mesmo consumindo a mão de obra disponível pela família exige contratação externa. O maior índice de lucratividade $(63,3 \%)$ foi observado no terceiro ano de produção.

\section{AGRADECIMENTOS}

Ao produtor, por ter fornecido e permitido a divulgação das informações relativas ao cultivo e os dados para a elaboração do custo de produção do urucum, em sua propriedade.

\section{REFERÊNCIAS BIBLIOGRÁFICAS}

CARVALHO, P. R. N.; SILVA, M. G.; FABRI, E. G.; TAVARES, P. E. R.; MARTINS, A. L. M.; SPATTI, L. R. Concentração de bixina e lipídeos em sementes de urucum da coleção do Instituto Agronômico (IAC). Bragantia, Campinas, v. 69, n. 3, p.519-524, 2010.

CORLETT, F. M. F.; BARROS, A. C. S. A.; VILLELA, F. A. Qualidade fisiológica de sementes de urucum armazenadas em diferentes ambientes e embalagens. Revista Brasileira de Sementes, Londrina, v. 29, n. 2, p.148-158, 2007.

CHR. HANSEN. A CHR. Hansen no Brasil. Disponível em: <http://www.chrhansen.com.br>. Acesso em: 19 set. 2011.

FRANCO, C. F. O. Mercado de urucum (Bixa olerrana L.) no Brasil. Artigo da Empresa Estadual de Pesquisa Agropecuária da Paraíba. Disponível em: <http://www.emepa.org.br>. Acesso em: 14 set. 2011.

FRANCO, C. F. O; SILVA, F. C. P.; CAZÉ FILHO, J.; BARREIRO NETO, M.; SÃO JOSÉ, A. R.; REBOUÇAS, T. N. H. Urucum: agronegócio de corantes naturais. João Pessoa: EMEPA-PB/SAIA, 2002. 120 p.

FRANCO, C. F. O.; FABRI, E. G.; BARREIRO NETO, M.; MANFIOLLI, M. H.; HARDER, M. N. C.; RUCKER, N. C. A. Urucum: sistemas de produção para o Brasil. João Pessoa: EMEPA / APTA, 2008. 112 p.

GHIRALDI, E. Corantes naturais mais comumente usados na indústria de alimentos. Disponível em: 〈http://www.uesb.com.br〉. Acesso em: 18 set. 2011.

LUPA. Levantamento censitário das unidades de produção agropecuária do Estado de São Paulo. Disponível em;

Cultura Agronômica, Ilha Solteira, v.24, n.1, p.93-102, 2015 
<http://www.cati.sp.gov.br/projetolupa/dadosmunicipais/pdf/t1.pdf $>$. Acesso em: 30 jan. 2012.

MAIA, A. H.; TARSITANO, M. A. A; SANTANA, A. L.; SILVA, F. C.; MARTINS, R. M. Estimativa do custo de produção de urucum em assentamento rural da Microrregião de Dracena/SP: alternativa de geração de renda ao pequeno produtor. In: CONGRESSO DA SOCIEDADE BRASILEIRA DE ECONOMIA, ADMINISTRAÇÃO E SOCIOLOGIA RURAL, 49., 2010, Belo Horizonte. Anais... Belo Horizonte: SOBER, 2010. p. 1-16.

MARTIN, N.; SERRA, R.; OLIVEIRA, M. D. M.; ANGELO, J. A.; OKAWA, H. Sistema integrado de custos agropecuários: CUSTAGRI. Informações econômicas, São Paulo, v. 28, n. 1, p.7-28, 1998.

NAKANO, L. C. G. Considerações sobre o plantio e extração do urucum (Bixa orellana L.) e sua utilização como corante. Arquivo de Ciências da Saúde, Umuarama, v. 2, n. 1, p.3339, 1998.

SANTANA, K. C.; GUEDES, P. A.; REBOUÇAS, T. N. H.; SÃO JOSÉ, A. R.; LEMOS, O. L.; VILA, M. T. R.; SOUZA, M. J. L. Teores de bixina em urucum (Bixa orellana) 'Piave vermelha', em diferentes acondicionamentos e temperaturas. Tecnologia e Ciência Agropecuária, João Pessoa, v. 2, n. 1, p.19-22, 2008.

TOCCHINI, L.; MERCADANTE, A. Z. Extração e determinação, por, CLAE, de bixina e norbixina em coloríficos. Ciência e Tecnologia de Alimentos, Campinas, v. 21, n. 3, p.310313, 2001. 